\title{
Research on the Inheritance Function of Wushu Culture in the Construction of School Wushu Education System
}

\author{
Yong Ding, Shuai Liu \\ Pingxiang University, Pingxiang, Jiangxi, 337055, China
}

Keywords: Wushu; culture; education

\begin{abstract}
The study of the cultural connotation of Chinese Wushu plays an important role in inheriting and promoting the national culture. Wushu culture can inspire the national spirit in the context of the collision of Eastern and Western cultures and the strong penetration of Western strong culture into China. The study of Wushu education is related to martial arts. The popularization and the martial arts culture in the primary and middle schools infiltration are imminent. Carrying forward and cultivating the national spirit have the very important role. This paper puts forward the contemporary significance of Wushu culture research and education research through the use of literature and comparative method.
\end{abstract}

\section{Introduction}

Wushu as a practical activity reflects human intelligence. Its movement pattern, various rules and regulations, concepts and knowledge system, as well as organization and propaganda organization necessary for recording and dissemination, clearly reflect that it is a kind of human social life unique cultural phenomenon [1-3]. According to Pang Pu's theory of "three cultural levels", Wushu culture can be divided into three layers: the outer layer is the object layer which is manifested as routines, exercises and instruments; inheritance and other rules and regulations; the innermost layer is the value layer of martial arts culture which is manifested as the essence, characteristic, value, ideological and theoretical foundation, and national character $[4,5]$.

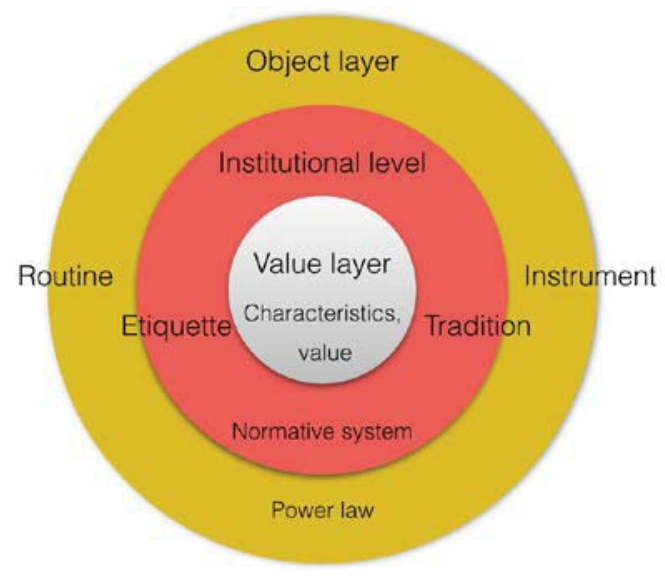

Figure 1. Wushu cultural structure 
In these three levels, the value of which are the core of martial arts culture. Martial arts are just movement patterns at best if lost it (Shown in Figure 1).

Cultural psychology is the soul of culture. And culture is the fundamental, then the value of martial arts culture is the core of martial arts culture. The Chinese Wushu grows and develops in the 5,000-year, and Chinese cultural soil are the excellent cultural heritage of the Chinese nation. They contain the philosophical and cultural connotations of life [6]. The Chinese classical philosophy is the theoretical basis of Chinese Wushu. Confucianism is the ideological basis of Chinese martial arts. Chinese ancient military art of war which is the principle of Chinese martial arts should be the basis of the development of traditional Chinese medicine. Chinese medicine, and Chinese Wushu provides a scientific basis; culture and arts make Chinese Wushu colorful [7, 8].

\section{The present situation of Wushu culture education in China}

\subsection{The cultural connotation of Wushu martial arts}

Wushu action is the unity of attack and defense. Attack and defense are dialectical unity, and are the premise of each other in the dynamic unity of Wushu to achieve the goal. Wushu defense is based on the principle of yin and yang balance, and is also based on the dialectical relationship between dynamic and static. They make a rational choice, rather than a simple passive defense, in the defense of the attack to defend for the attack and pay attention to offensive and defensive balance to defense as an offensive. Such as Taijiquan "to soft grams", "in the static brake", seemingly "inaction", "less empty", they in fact imply murder. As for the martial arts demonstrated by the deep and deep spirit, perseverance and decisiveness of the spirit, agile and brave qualifications, it is necessary for the Wushu essential elements, otherwise I am afraid it is difficult to get a true biography, even by the true mass. It can not achieve martial arts repair for the highest level. Wushu is a martial arts show, and martial arts who use it as a moral standard is actually a combination of moral standards and spiritual values. It is precisely because this concept makes the Chinese Wushu after thousands of years of development to continue to endure.

\subsection{The cultural connotation of Wushu routine}

Chinese martial arts repertoire is a unique form of movement. It is different from any country as a unique form of national fighting. Wushu routine is by no means a simple synthesis of action plus action. It is from the idea of each action, operation, to how to start, how to end, how to make the transition between action, and how to make external action and human inner harmony. These are full of wisdom and ideals of the Chinese people.

Table 1. Survey of Wushu content which students are interested in

\begin{tabular}{cccc}
\hline Characteristic & $\begin{array}{c}\text { Number of } \\
\text { times }\end{array}$ & Frequency & Sort \\
\hline The road of unarmed & 114 & $36.3 \%$ & 3 \\
Instrumental routine & 126 & $40.1 \%$ & 2 \\
Sanda & 214 & $68.2 \%$ & 1 \\
Power law & 50 & $15.9 \%$ & 4 \\
Other & 28 & $9.0 \%$ & 5 \\
\hline
\end{tabular}


The students were interested in martial arts programs as follows (see in Table 1): routine (hand and equipment routine), Sanda, exercises, and the proportion is $76.4 \%$, $68.2 \%, 15.9 \%$ respectively. Thus, the routine is one of the students' favorite martial arts content. Routine movement is the main form of traditional martial arts, and martial arts is the main form of transmission, promotion, competition, or strive to enter the Olympic martial arts competition form. They can not "desalination", but should be based on student interest and needs "optimization routines".

\section{Problems in Wushu culture education}

Although Wushu has received more and more attention, but Wushu teaching in the country has not achieved a fundamental universal. It did not cause the attention of schools at all levels. However, under the impact of Western competitive culture, the practice of martial arts teaching is based on the competitive sports teaching model with heavier utilitarian thoughts. The result is that Wushu is not traditional and non-characteristic. And non-ethnic development pattern which is the transmission of Wushu to traditional culture value and significance are gradually withered away. In college sports culture teaching, the western sports culture-oriented university competitive sports focus on the pursuit of "higher, faster, stronger", advocating individual freedom, advocating individual competition, and focusing on the shape of the human body But the lack of awareness tempering, easy to overlook the ideological and moral qualities of students and patriotic education or a mere formality, these all things make students feeling boring. Most of PE teachers are not good at excavating the intrinsic educational factors of teaching materials, and guiding college students correctly So that the words and deeds of some college students in sports activities deviate from the sports ethics.

\section{The inheritance of Wushu culture in school education}

\subsection{The value of Wushu culture to cultivate students' personality}

Confucian philosophy emphasizes "benevolence, righteousness, courtesy and faith", and it has deeply influenced the Chinese Wushu's ethical thought which became its foundation and core. First of all, the founder of the Confucian doctrine attaches great importance to moral character. The German on the supremacy of the status leads to the Chinese martial arts re-take ceremony of the characteristics. Secondly, Confucianism advocated being self-denial, righteousness and lightness, modest and prudent, down to earth. The ideal personality is humble treat people, prudent subtle, strict self-discipline, wide to treat people, open-minded "modest gentleman". Boxing together, not only exercise, there are important deep meaning to save Yan. Wushu teaching fully taps the culture of martial arts to cultivate human values. Martial arts technical skills at the same time, improve the student's personality. 


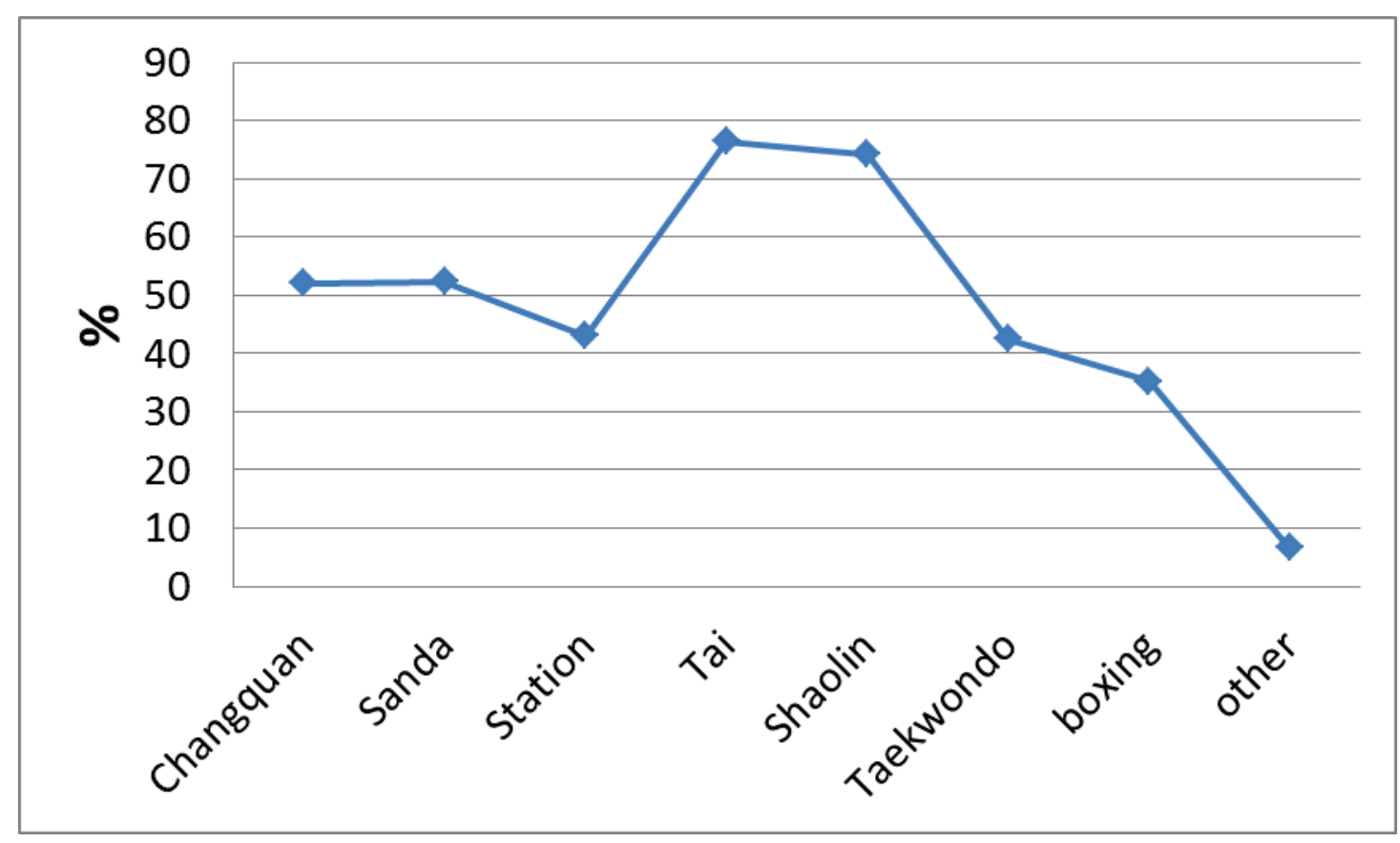

Figure 2. The survey graph about the Wushu cognition of student

Students' understanding of Wushu is rather vague. As shown in Figure 2, for a wide range of tai chi, Shaolin boxing is respectively 76.6\%, 76.2\%; and Sanda and Changquan is only $53.9 \%, 51.9 \%$. Students think they belong to martial arts projects. $42.6 \%$ and $25.4 \%$ of students believe that taekwondo and boxing are martial arts projects.

\subsection{Key points of inheritance of Wushu culture and education}

(1) The change of educational theory. When the martial arts are facing the world and the Chinese traditional culture is watered down in the students' mind, the idea of Wushu education must be changed. It is necessary to teach Wushu technology to realize the concept of "health first". To teach Wushu related traditional culture. "Inheritance of martial arts culture" concept, the two are mutually unified.

National education authorities should be martial arts schools at all levels as a compulsory course. To enhance the status of martial arts, martial arts disseminate the development of a more extensive and smooth, and the development of relevant rules and regulations To ensure that the martial arts lessons in the school's extensive heritage.

(2) Strengthen the construction of Wushu teachers. Because of the lack of martial arts culture, Wushu education can not play the role of disseminating Wushu culture, cultivating and carrying forward the national spirit. All kinds of schools at all levels should strengthen the construction of martial arts teachers. To strengthen the traditional culture and education, culture and martial arts training need excellent martial arts professional teachers. Schools at all levels provide the necessary protection, and schools at all levels should pay attention to martial arts teachers' ff the further education and training.

(3) Ensure the necessary venues, equipment, facilities, capital investment. Martial arts equipment which has a certain martial arts cultural connotation has a certain educational value. Such as martial arts games are made with silk clothing, and 
reflect the traditional characteristics of China's ancient silk. Martial arts performances have a unique aesthetic value. Therefore, we should pay attention to the material aspects of martial arts capital investment to ensure the smooth development of martial arts.

(4) Focus on Wushu Classroom Teaching. Wushu teaching time is limited, and in the teaching hours it can not increase the case. So we should consider how those who can represent all forms of martial arts martial arts content to set martial arts teaching content. The content of Wushu teaching content should be set up with some to promote the healthy development of students, and enhance the physical content of the technical content of students. The traditional culture that embodies the cultural background of Wushu movement should be selectively set as the content of Wushu teaching. So the students can understand the long-term Wushu culture from the angle of participating in Wushu movement.

\section{Summary}

Wushu as an outstanding national sport of the Chinese nation has been accepted and recognized by the Chinese people and the rest of the world. And it is being integrated into the world sports culture. In the development of contemporary martial arts movement, we should strengthen its education inheritance, promote the localized education of Wushu movement, and regard Wushu as an entry point of internationalization of Chinese national sport and promote the internationalization of Wushu movement. Therefore, we should deeply study the development of traditional Chinese Wushu culture and inheritance. Its historical education inheritance characteristics, the localization of modern martial arts movement and international education achieve a wide range of Wushu culture.

\section{References}

[1]. Li X, Department P S. Wushu Culture on College Students' Moral Education[J]. Wushu Science, 2014.

[2]. Guo Z H, Bai J X. A Wushu cultural interpretation of Anshun local drama.[J]. Journal of Physical Education, 2013.

[3]. YANG You-feng. Development of the Water Margin Wushu culture[J]. Journal of Sports Adult Education, 2012.

[4]. Kang T, Lin M A, Education S O, et al. Reflection of Inheritance Development of Chinese Wushu Intangible Cultural Heritage[J]. China School Physical Education, 2015.

[5]. Guo Q, Yu Q, Liu Y, et al. On the Value of College Education Inheritance of Wushu as Intangible Cultural Heritage[J]. Wushu Science, 2014.

[6]. Shan-Shan L I, Liu L. Wushu culture education in primary and secondary schools[J]. Shandong Sports Science \& Technology, 2013.

[7]. Lu X. On the Culture Education of the Contemporary Wushu Education[J]. Wushu Science, 2013.

[8]. Shang B. On Wushu Culture Education in College Wushu Teaching[J]. Wushu Science, 2013. 